\title{
Autonomous Driving - Political, Legal, Social, and Sustainability Dimensions
}

\author{
Miranda A. Schreurs, Sibyl D. Steuwer
}

\section{Content}

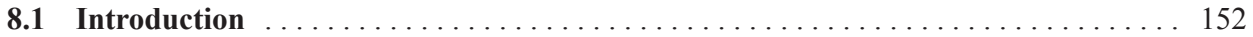

8.2 Autonomous driving from an innovation policy perspective $\ldots \ldots \ldots \ldots \ldots \ldots \ldots 2$

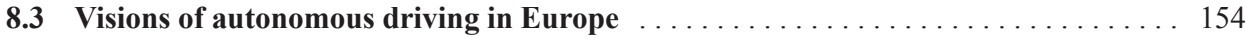

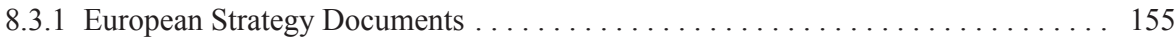

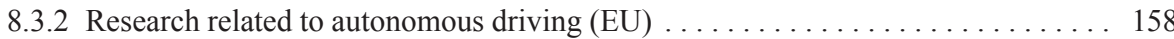

8.3.3 Actors and arenas for autonomous driving in the EU . . . . . . . . . . . . 160

8.4 National and international legislative and political developments $\ldots \ldots \ldots \ldots \ldots 1$

8.4.1 Regulatory Changes to the United Nations Convention on Road Traffic

(Vienna Convention) ................................. 161

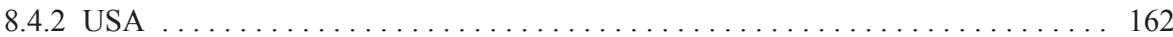

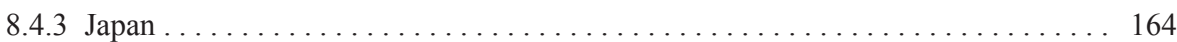

8.4 .4 United Kingdom . . . . . . . . . . . . . . . . . . . . . . . . . . . . . 164

8.4 .5 Sweden . . . . . . . . . . . . . . . . . . . . . . . . . . . . . 164

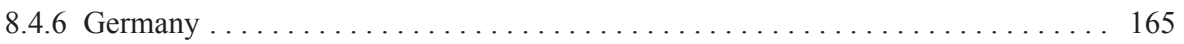

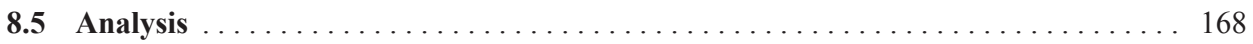

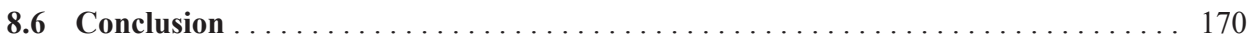

References ........................................ 170

M. Schreurs ( $\square)$

Freie Universität Berlin, Forschungszentrum für Umweltpolitik, Deutschland

Miranda.Schreurs@fu-berlin.de

S. D. Steuwer

Freie Universität Berlin, Forschungszentrum für Umweltpolitik, Deutschland sibyl.steuwer@fu-berlin.de 


\subsection{Introduction}

Autonomous driving (self-driving) vehicles, once just a science fiction dream, are a growing reality. Although not commercially available, rapid advancements in technology are creating a situation where technological development needs are moving beyond the regulatory environment. Technological developments have put pressure on governments to make regulatory changes permitting on-road testing of autonomous vehicles. Nevada became the first government worldwide to provide licenses for the testing and operation of autonomous vehicles in the state albeit under strict conditions. The Nevada Department of Motor Vehicles requires that "when autonomous vehicles are eventually made available for public use, motorists will be required to obtain a special driver license endorsement" [8]. Other states have followed Nevada's lead. New regulations in the United States have provoked the question of whether regulatory changes are necessary in Europe as well. This chapter examines the emerging competition among automobile manufacturers related to the development and deployment of autonomous vehicles and their political and regulatory implications. Special attention is paid to the role of industrial stakeholders and political actors in relation to the development, uptake, and regulation of autonomous vehicle technologies. This is done from a comparative perspective considering developments in the United States, the European Union, the United Kingdom, Germany, Sweden, and Japan. The different framings of autonomous vehicle technologies and their potential contributions are also considered.

\subsection{Autonomous driving from an innovation policy perspective}

Increasing vehicle automation can be understood as an innovation process that may eventually lead to autonomous or semi-autonomous vehicles. Innovations can be classified according to the kind of innovation (e.g. product, process, organizational), the phases of innovation (invention, innovation, diffusion) or the magnitude of innovation (ranging from incremental to radical). A variety of influencing factors shape innovation processes. These include actors and actor networks, institutional frameworks, and technological developments both inside the innovation system and external to it. There may be co-evolutionary development of (technological) innovations and influencing factors [35]. Political intervention is one factor that can influence innovation processes and is our focus below.

Automated technologies have been incorporated into cars for decades, including anti-lock brakes, rear view alarm systems, lane departure warning systems, and adaptive cruise control. Information and communication technologies are likely to make possible the rapid deployment of some automated technologies (as is already the case with automated braking systems). Automated driving technologies could improve emergency response, enhance public transport systems, and optimize intermodal passenger transport.

Autonomous vehicle technology is now rapidly developing as autonomous driving vehicles are tested on the road. Various future development paths are possible as indicated 
by the use cases described in the chapters by Wachenfeld (Ch. 2, see also Beiker in this book Ch. 14). Autonomous vehicle technology development paths range from incremental (e.g. automatic braking systems and transmission systems) to larger (automated crash avoidance safety systems and autonomous valet parking) to revolutionary changes to existing systems (fully autonomous vehicles in regular traffic) (for a definition and nomenclature see e. g. [25]). Depending on the state of a technology and the degree to which it has been implemented, there are different policy implications and regulatory intervention needs.

Different technological and use paths place different demands on the policy system. Incremental technological changes can usually be addressed with relatively minor changes to existing regulatory frameworks. More radical technological changes, such as the fully autonomous vehicle, will require deeper regulatory interventions as well as societal awareness raising and acceptance. The information and communication technologies (ICT) used in autonomous vehicles could also raise various questions related to data protection and storage although this will depend very much on the kind of technologies employed (Ch. 24).

Certainly one of the changes visible in relation to the emergence of autonomous vehicle technology is the emergence of new stakeholders. The technologies involved have widened the field of actors engaged in transport policies and led to the formation of new political coalitions. The ICT industries are important stakeholders in autonomous vehicle technologies and policies. Auto manufacturers and other players (like Google) are both in competition in the development of prototypes and in co-operation with each other in an effort to achieve a more favorable regulatory environment for the testing of autonomous vehicle technology.

The commercialization of autonomous vehicles is envisioned in the coming years by some manufacturers although there is considerable uncertainty as to when and if the technology will be made commercially available any time soon. Conditions for commercialization may also vary significantly country to country depending on road traffic conditions. While there are many questions as to whether commercialization is realistic in the near future, expert communities are urging regulators to prepare. In some jurisdictions (especially in the United States) early preparatory steps for potential deeper regulatory changes are being taken.

The speed and quality of advancements in autonomous driving technologies will impact demands for political intervention and steering. Many political interventions are driven by technological advancements. In the case of incremental technology development, there may be a parallel process of incremental regulatory changes, licensing decisions, or increase or decrease in financial or other political support schemes.

Incremental technological changes can be researched from the perspective of systems innovation theory, where innovations are understood as a result of multilateral interaction processes among firms, industries, organizations, and institutional frameworks [13], [14]. In the case of more revolutionary technological developments, which result in more disruptive changes to the status quo, politicians may be forced to make rapid and major regu- 
latory decisions with little preparatory or learning time and with few existing experiences to draw upon.

In some cases, political actors may decide to try to accelerate the development of certain technologies and their large scale application. We have seen examples of policy-driven development with, for example, nuclear and renewable energies. In these cases, governments set incentives to support the development of these technologies, e. g. with research and development funding, support schemes, loans, the provision of infrastructure, and the taking over of liability risks even though in some countries, there were later decisions to phase out the use of a particular technology. There are also various examples in the transport sector, where state actors aimed at paving the way for certain technological choices. Apart from providing road infrastructure and thereby supporting individual automotive transport systems, e-mobility is a recent example of an attempt by policy-makers to help boost the implementation of a particular technology on a larger scale [9].

Policy makers do not typically like to intervene in the workings of market economies but at times may feel pressured to do so. As Edquist formulates it, "[t]here must be a 'problem' - which is not automatically solved by market forces and capitalist actors - for public intervention to be considered" [14].

Different factors may be behind a decision to support new technologies or technological applications. Policy makers may choose to promote a technology's development in order to support the competitiveness of a domestic industry, in response to problem-pressures (e. g. safety or environmental factors), to experiment with new technological possibilities, or in reaction to international developments. As Edler and his colleagues put it: "Public innovation policy aims to strengthen the competitiveness of the economy or of selected sectors, in order to increase social welfare through knowledge creation and economic success" [12]. Numerous studies illustrate the importance of political intervention especially in the field of environmental policy innovation (see e.g. [30], [31], [32]).

There are several ways political actors can support the development and diffusion of new technologies. They may encourage and support the development of expert networks, finance research and development, create demand for a certain technology (e. g. by setting up support schemes or mandating government purchasing of a technology), and, by providing basic infrastructure (for a summary of approaches see [35]). Research support has been relevant in the development of autonomous vehicle technologies as well. States that are lagging behind in the technology are now scrambling to catch up. Since innovations go through various phases (see e.g. [26], [36]), governmental interventions may also be limited to particular innovation stages of a technology.

\subsection{Visions of autonomous driving in Europe}

Visions of the future can both influence and reflect regulatory debates and their public perception. Visions for autonomous driving are being shaped by various stakeholders who have their own interests in advancing particular framings. When particular framings of a 
technology take hold, they have the potential to direct future R\&D trajectories and other societal and political actions. As we will see below, autonomous vehicle technologies are increasingly being viewed as an important component of future transport systems. Their development is being linked to concerns about industrial competitiveness, sustainable development, resource efficiency, safety, and assistance for the elderly and others who might otherwise not be able to drive a car. At the same time, there are some voices of concern that there could be a loss of control through robotization of automobiles. Here we consider how autonomous driving is discussed at the European level before turning further below to discussions in other economies.

To understand how autonomous driving vehicles are being discussed at the European level, we looked at strategy documents, European-funded research projects, and important networks related to autonomous driving. The analysis shows something of a mismatch between the interests of specific industrial actors in a rapid commercialization of autonomous driving technologies with broader European visions and objectives in the transport area in which autonomous driving technologies play some role, but little attention is given to autonomous vehicle technologies. Autonomous driving technologies are not widely discussed in European strategic documents although some research projects are being funded. This could be important since the extent of attention given to a subject and the visions associated with it may determine whether or not political support is lent to a technology's development. With little explicit attention given to autonomous driving vehicles at the European level, little political action can be expected unless there are either sudden technological innovation shocks or stronger political lobbying by stakeholders.

\subsubsection{European Strategy Documents}

Autonomous driving technologies have received little attention to date in European Commission strategic documents, including roadmaps, green papers, and white papers. To the extent autonomous vehicle technologies are discussed it is often in the context of broader EU debates on European competitiveness, innovation, climate protection, energy security, employment, and education (the EU 2020 strategy) [17].

Guided by the general framework objectives of the EU 2020 strategy, the following documents were analyzed: "Roadmap to a Single European Transport Area - Towards a competitive and resource efficient transport system" [18], "Research and innovation for Europe's future mobility. Developing a European transport-technology strategy" [19], the "CARS 2020: Action Plan for a competitive and sustainable automotive industry in Europe" [20], and the "Directive on Intelligent Transport Systems" [24]. These strategic documents cover issues linked to autonomous driving: mobility, infrastructure, digitalization, and general European discourses related to innovation and climate protection. The documents differ in their degree of specificity.

These documents shed light on which actors are taking up autonomous vehicle developments and give an impression of how far reaching the debate on autonomous driving 
currently is in Europe. They also give a picture of how autonomous driving technology is being framed and which other societal, technological, and political issues it is being linked to. Finally - and maybe most importantly - these documents hint at the opportunities for and obstacles to the wider implementation of autonomous vehicle technologies at the European level.

\subsubsection{Competitiveness and Innovation}

The European Union has as one of its goals the strengthening of the competitiveness of European industry and technological leadership including in important sectors like transport. The European Union's transport roadmap stresses that "innovation is essential" to maintaining European competitiveness. Three areas of innovation that are stressed are: "efficiency through new engines, material, and design", "cleaner energy use", and "safer and more secure operations through information and communication systems" [18].

The communication document from the European Commission to the Parliament and the Council with the title "Research and innovation for Europe's future mobility. Developing a European transport-technology strategy" [19] can be seen as the starting point for the development of a strategic transport-technology plan. At its visionary core is the expected change towards high value-added, innovative transport technologies. The transport industry of the future is expected to have to deal with highly complex mobility systems and to achieve this with a much lower carbon content. New materials, new production processes and new technology partners as well as "a stronger cross-fertilisation between the transport modes" are seen as crucial elements of this industry transition. The communication further stresses the expectation that the transport sector, the energy sector and information and communication technologies will be increasingly intertwined.

With regard to the automotive industry, strengthening competitiveness is central to European policy-makers. This is reflected by the CARS 2020 Action Plan, which was developed by DG ENTR (Directorate-general for Enterprise and Industry). The Competitive Automotive Regulatory System for the 21 st century (CARS 21), the antecessor to CARS 2020 , is concerned with overcoming the economic crisis in general and the crisis of the European automotive industry in particular. It sets a vision of: "An automotive industry that is leading in technology, in coordinated action with the fuel supplier industry, producing vehicles which are attractive to EU consumers, clean in terms of regulated pollutants, more fuel-efficient, safe, quiet and connected" [20].

\subsubsection{Efficiency and sustainability}

At the European level, innovation is often linked to the development of an energy and resource-efficient and sustainable transport system. The transport roadmap spells out "A vision for a competitive and sustainable transport system". The document highlights the dual goal of increasing transport and mobility within the Union while reducing greenhouse gas emissions by $60 \%$ until 2050. It further links EU 2020 and its flagship initiative on resource efficiency to transport policy. This translates into a transport system that must use "less and cleaner energy, better exploit a modern infrastructure and reduce its negative 
impact on the environment and key natural assets like water, land and ecosystems" [18]. The document preparing the transport-technology strategy repeatedly stresses the EU's vision to strengthen competitiveness by decarbonizing the transport system and accordingly calls for research in green technologies, material substitutions, and ICT in order to optimize intermodal and public transport and thereby enhance efficiency [19]. The CARS 2020 action plan also establishes a strong link between competitiveness and clean and green vehicles [20].

\subsubsection{Harmonization and coordination}

Realizing a single European market is at the heart of all European strategic documents related to transportation. This is a factor in the strong push for greater harmonization and coordination of national policies. The transport roadmap highlights the importance the EU Commission attaches to harmonization; here it is argued that "a situation where (for example) one Member State opted exclusively for electric cars and another only for biofuels would destroy the concept of free travel across Europe." It also illustrates that the EU Commission aims at influencing technology development.

Also in the CARS 2020 action plan the fragmentation of vehicle regulation among EU Member States is considered problematic. The European Commission has called for more co-ordination and standardization [20]. In the CARS 21 process, Europe's role in standardization has been highlighted. European Commission Vice-President Neelie Kroes "underlined the business opportunities created by making vehicles digital and connected, which requires public support for funding and standardization" [4]. CARS 2020 mentions the deployment of Intelligent Transport Systems (ITS) with reference to the automatic emergency call system, eCall as a particular organizational challenge, which demands strong coordination [20].

\subsubsection{Safety}

The "vision zero" which refers to the goal of eliminating traffic fatalities and injuries by 2050 is a key selling point for the industry. Safety is also addressed in the transport roadmap, although it receives considerably less attention compared to other issues, such as competitiveness, sustainability, resource-efficiency, or innovation.

The "vision zero" is mentioned as the ninth of ten goals of the transport roadmap. In line with this goal, the EU aims at halving road casualties by 2020. The EU is to be a world leader in safety and security of transport in all modes of transport [18]. Annex I spells out how to approach that goal and mentions - besides training and education - technological solutions such as "driver assistance systems, (smart) speed limiters, seat-belt reminders, eCall, cooperative systems and vehicle-infrastructure interfaces." These can be seen as steps towards a general increase in automation and employment of information and communication technologies.

While the Directive on Intelligent Transport Systems puts comparatively high priority on an increase in safety through the application of information and communication technology, it does not explicitly speak of autonomous driving [24]. 


\subsubsection{Summary}

The document, "Research and innovation for Europe's future mobility. Developing a European transport-technology strategy" [19] is where one might expect autonomous driving to be discussed as the communication addresses research, innovation, and mobility issues. Yet, while the term 'smart' occurs repeatedly in the text, neither 'autonomous' nor 'driverless vehicles' are mentioned. 'Intelligent' and 'automated' are mentioned only once in the context of transport infrastructure: "Modern infrastructure will increasingly incorporate new components which make it smart (intelligent, ICT-enabled and automated), green (new light and recyclable materials) and intermodal (automated terminals, hubs, and equipment). It will integrate the provision of alternative, low carbon fuels and innovative management and operation systems" [19].

Also with regard to research and innovation, autonomous driving is not discussed in the transport-technology strategy document although it could be argued that smart mobility is related to autonomous driving. Many of the visions described in the strategic document can be seen as being linked to autonomous vehicles, such as the interdependence between information and communication technologies and the transport system. Yet the main focus is on green technologies, material substitution and ICT and the optimization of intermodal transport.

Similarly, autonomous driving is not explicitly mentioned in the transport roadmap. Rather, intelligent transport systems, new communication services, and improved traffic management and information systems are seen as future opportunities to optimize traffic flow and reduce congestion and it is in this context that there are calls for further research and innovation. Links are made to multimodality and optimization of the use of infrastructure. Increased automation is not discussed centrally in relation to the modernization of the automotive industry in Europe. It is not even mentioned as an explicit topic in the CARS 2020 action plan.

The Directive on Intelligent Transport Systems, supported by DG Transport, targets steps to be taken towards the application of ITS and thus could be argued to touch upon aspects of autonomous driving, but does not explicitly mention the term or similar terms [24].

In summary, it can be said that while developments related to autonomous driving are mentioned in major strategic and vision documents, autonomous vehicles or autonomous driving are as such not firmly embraced by European bureaucrats or politicians.

\subsubsection{Research related to autonomous driving (EU)}

Somewhat more attention to autonomous vehicle technologies is being paid in Europeanfunded research projects. There are various research projects funded by EU institutions that could impact autonomous driving. eCall is an initiative to bring rapid assistance to motorists involved in accidents. The Galileo project is a civilian global satellite-based navigation system. TAXISAT, is a related global navigation satellite system being developed for taxis. The SARTRE project, which is funded under the European Union's Framework 7 program, 
aims at advancing platooning (convoying to make more efficient use of road space). The project HAVE-it follows a long-term vision of autonomous driving and aims at high levels of automation. The purpose of the project is to "develop, validate and demonstrate important intermediate steps towards highly automated driving" such as advanced driver assistance systems. The research project, "SMART- New services enabled by the connected car", focused on the implication, benefits, and services of connected cars. The project's final report concluded that the connected car may make better use of infrastructure and will increase safety as well as fuel efficiency. The EU project "Citymobil Advanced Transport for the Urban Environment" looked at automated public transport systems and some showcases (e.g. La Rochelle, Heathrow) with the aim of bringing the implementation of these public transport systems in cities one step further. An example of a joint public-private R\&D initiative supported by various directorates-general (RTD Research and Innovation, CNECT - Communications Networks, Content and Technology, ENER - Energy, ENV - Environment, ENTR - Enterprise and Industry) in the vehicle area is the European Green Cars Initiative launched in 2009 and with a priority on the development of efficient, safe, and environmentally friendly mobility, especially electro-mobility. Another important project is AdaptIVe, a successor to InteractIVe. Started in January 2014 and funded by the European Union's Framework 7 Program, this consortium of 29 partners aims to demonstrate the potentials for automated driving in complex traffic environments while addressing some legal issues related to levels 1 to 4 of the SAE classification system.

Currently, the European Union is supporting research on autonomous driving within its framework research support scheme, "Horizon 2020". There are several entry points for research on autonomous vehicles under the Horizon 2020 work program on leadership in enabling and industrial technologies in the section on Information and Communication Technologies [22]. Research for the transport sector is funded via the work program's section 11 on smart, green and integrated transport. Here, autonomous driving is explicitly mentioned: "Automated and progressively autonomous driving applications in road transport, actively interacting with their intelligent environment could provide an answer to the EU objective of reconciling growing mobility needs with more efficient transport operations, lower environmental impacts and increased road safety" [21]. Apart from technical aspects including research on Advanced Driver Assistance Services, other aspects are supported such as behavioral aspects of driving (users' responses to technology and on-board infrastructure, conditions of attention/loss of attention, etc.), ethical and gender issues as well as liability and standardization questions. The aim is to enhance the technology's robustness and effectiveness in real-life situations.

In sum, research funded by the EU addresses various aspects of vehicle automation, the linking of information and communication systems to enhance efficiency, and research into autonomous vehicle technologies. There are growing signs of interest in the legal and societal implications of various automation levels and efforts to develop common definitions of vehicle automation levels. In the future, there will be need for more research on legal and societal questions tied to the greater use of automation in the transport sector. 


\subsubsection{Actors and arenas for autonomous driving in the EU}

At the European level, different Directorates General (DG) are involved with questions addressing autonomous driving, with DG Connect being somewhat more engaged than for example, DG Mobility and Transport (MOVE) or DG for Enterprise and Industry (ENTR). In general, the EU Commission's interests in the transport area are more related to strengthening competitiveness throughout the whole Union including in remote areas (by e.g. supporting basic infrastructure development) and combatting climate change (i. e. e-mobility, urban development that supports public transport, bicycles, etc.) and not so much on implementing a vision of widespread use of autonomous driving vehicles.

DG Connect supports research in the field of automated mobility. It mainly addresses the research on intelligent transport systems (ITS) and highlights the role of ICT for ITS and mobility for it helps to reduce greenhouse gas emissions, increases energy efficiency in the transport sector, and enhances safety and mobility for people and goods in general. ICT is, however, mostly connected to the provision of real-time traffic information and not explicitly to autonomous road vehicles.

Information on autonomous driving is generally best assessed from DG Connect. While various aspects and projects are listed on their website, DG Connect forwards the reader to the iMobility Forum when looking for 'Automated Driving'. iMobility is one of the two main platforms on the European level that addresses vehicle automation. Via the iMobility Forum, the Commission is in contact with stakeholders. The platform is chaired by DG Connect and co-chaired by ERTICO-ITS Europe as well as the European Automobile Manufacturers Association (ACEA) and the European Association with tolled motorways, bridges and tunnels (ASECAP). Within iMobility, there is a working group on vehicle road automation. DG Connect partly finances this network. The iMobility Forum is linked to the ERTICO platform on intelligent transport systems in Europe. It was founded as a joint initiative by the European Commission, national transport ministries as well as industry representatives and aims to be a networking platform to spur exchange between actors and stakeholders related to all kinds of aspects of intelligent transport systems. It gives an overview of various research projects and activities in European Member States on ITS and accordingly, automated vehicles [16].

In addition, the European Union provides a platform for debating visions of the future: FUTURIUM, part of the Digital Agenda of Europe. Several articles about autonomous driving can be found here.

To summarize, autonomous driving is not strategically anchored in European policy-making. The overarching discourses and objectives in the European transport sector can be subsumed under the headlines "competitiveness", "sustainability", "efficiency", "low-carbon" and, to a lesser degree, "safety". While autonomous driving can arguably contribute to any of these overarching objectives, stakeholders have not yet made much effort to make these links. The actors most actively addressing autonomous driving at the EU level deal with communication technologies, smart mobility, and intelligent transport systems (DG Connect including links to the EU's vision for the Digital Europe). The auto- 
motive industry is mainly represented by its association. Individual companies do not appear very active on this issue at the EU-level. Autonomous driving is still in the realm of research rather than implementation and there exists no delineable vision for a future where autonomous vehicles play a major role. The cases addressed in this book do not play a role at the European level. In addition, there is a lack of integration of the topic into existing visions on transport and mobility. The needs for regulation and further research and development are being discussed in working groups both at the European and the German national levels, although autonomous driving is not high on the political agenda in either case. While the European Commission's administration is (co-) funding some of these initiatives, it has not taken a lead on the regulatory front; rather it is mostly active in supporting research and development. This is similar to the case in Germany. The issue of autonomous driving is on the radar screen of the German transport ministry and major associations but is only now slowly beginning to gain somewhat more attention. As is discussed further below, one relatively important new development is the reform of the United Nations Convention on Traffic Safety of 1968 that has been pushed by European automakers concerned about losing ground to international competitors. Next on their agenda is likely to be enabling legislation at the national level for testing purposes.

\subsection{National and international legislative and political developments}

There are some differences in national discourses and support strategies for autonomous vehicles in major automobile producing markets and in the European Union. Below we consider developments in the United States, Japan, the European Union, the United Kingdom, Sweden and Germany. A common characteristic of these countries and the EU is that they lack national regulations for autonomous vehicles. It has been with state-level regulations in the United States and special permits in the case of European countries that test driving of self-driving cars has begun on the public roads [33].

\subsubsection{Regulatory Changes to the United Nations Convention on Road Traffic (Vienna Convention)}

Reacting to developments in the United States, at the European level debates about the need for modifying the United Nations Convention on Road Traffic (the Vienna Convention) which had been on-going for about a decade, intensified. Article 8, paragraph 5, of the 1968 convention states: "Every driver shall at all times be able to control his vehicle or to guide his animals" [7]. Before Google pushed the debate forward, there was considerable disagreement among experts as to how much of an obstacle the Vienna Convention was. Google's release of its Self-Driving Car tipped the scale in the direction of regulatory change. As reported by Euractiv in the summer of 2013: "The EU is currently slightly 
lagging behind the US. Autonomous driving is forging ahead in the US where steps are currently being taken to advance the technology by states adopting laws allowing for public road testing. However, Europe continues to lag behind the US with restrictive legislation that could, for the foreseeable future, effectively prevent the introduction of more advanced autonomous driving systems". The report notes that "while the technology is ready, appropriate infrastructures and legal framework are still missing" [34]. In May 2014, the governments of Germany, Italy, France, Belgium, and Austria jointly proposed an amendment that was agreed to by the U.N. Working Party on Road Traffic Safety. The amendment would allow self-driving technologies as long as the system "can be overridden or switched off by the driver" [40]. If agreed upon by the parties to the convention, this could ease conditions for research and development of autonomous vehicles in many countries. For a more critical discussion see also section 8.4.6.

\subsubsection{USA}

The United States is the most advanced nation in terms of introducing autonomous driving vehicles into its transport system. Legislation on autonomous driving has been passed in California, Michigan, Nevada, Florida, and the District of Columbia. In another six states - Arizona, Colorado, New Hampshire, Oklahoma, Oregon, Texas - the legislative attempts failed or are pending. There are another dozen states with ongoing regulatory initiatives. Some common features of their regulation regard the definitions of autonomous driving and autonomous vehicles employed and the conditions for obtaining operation and testing permission. Liability issues are also beginning to gain attention. California has set a 2015 deadline for the establishment of liability rules [51]. The newly enacted legislation in the United States has been developed with an eye towards allowing the testing of autonomous driving vehicles; most existing legislation is very restrictive regarding their use. At this stage neither the US government nor the automotive industries want to take large risks in relation to a technology that is still in an early development stage and that must still prove its reliability and safety. The same could be said for the other countries looked at here.

Regulatory initiatives in the United States were a direct response to Google's push for legal clarification regarding the status of autonomous vehicles. Google, an active developer of self-driving software and technology, has lobbied state by state for the legislation enabling the operation of self-driving vehicles.

Various US politicians have strongly spoken up for the technology. Governors and other state politicians have on various occasions praised autonomous vehicles in public and claimed their leadership relative to other states by being frontrunners in passing supportive legislation.

Nevada Governor Brian Sandoval in early summer 2011 upon the passage of his state's first law on autonomous driving vehicles stated: "Nevada is the first state in the country that is going to be (adopting) regulations for this vehicle (...) I think it is important for Nevada to be first on this. This is going to be part of the future and Nevada has always been 
a very progressive state" [52]. In the Florida Senate, Republican Jeff Brandes sponsored an autonomous driving bill stating, "this legislation is about vision and leadership for the 21 st Century world and forges a path for future innovative economic opportunities for Floridians" [42]. In September, when signing autonomous driving into law, California Governor Jerry Brown pointed out that he sees autonomous vehicles as "another example of how California's technological leadership is turning today's science fiction into tomorrow's reality. (...) This law will allow California's pioneering engineers to safely test and implement this amazing new technology" [2]. Noting that the state was slipping behind competitors, Michigan's Governor Rick Snyder urged action. In his State of the State Speech in January 2013 the governor lamented: "They [California, Nevada and Florida] are ahead of us, and aren't we the automotive capital of the world?" [5]. These examples give a clear impression of how politicians are starting to see autonomous vehicle technology and why they are promoting autonomous driving. For the leaders of these pioneering states, autonomous driving is seen as a sign of being on the technological cutting edge. The technology's developers stress the safety benefits expected to come with the implementation of the technology, the increased comfort it will provide for elderly people, and the reduction in traffic congestion it should bring about.

Google has been an important entrepreneur that has stimulated both technological and regulatory developments. Google is a new and non-traditional player in transport, a sector which until now has been dominated by the automotive industry. With its retrofitting of automobiles with robotic software, the IT-company has challenged the automotive industry to innovate in new directions (Chapter 10). As noted above it has also put regulators under pressure to take action. Indeed, regulations have had to catch up with the technological innovations. Google's actions have also pushed self-driving technologies onto the international agenda. It has opened up new research agendas and challenged policy makers and legal experts to consider the technological and social meanings of this rapidly developing new technology. In the European Union as well as internationally, it is also leading to discussions about the need for early harmonization of standards so as to prevent the institutionalization of incompatible standards in different world regions, e. g. via United Nations Economic Commission for Europe (UNECE) regulations and vehicle type approvals that make sure that a vehicle's design conforms to technical requirements. Beyond these issues, the role of ICT in the automotive industry of the future and very importantly, data protection concerns, will need societal debates and decisions.

In May 2013, the National Highway Traffic Safety Administration (NHTSA) established an official classification scheme for vehicles which range from level 0 where the driver is in complete control of the vehicle at all times to level 4 where the vehicle performs all safety-critical functions and monitors roadway conditions for the entire trip and could include unoccupied cars. The intermediary levels make increasing use of autonomous vehicle technologies. The NHTSA also issued recommendations to aid states as they make regulatory decisions regarding vehicles with new technological capacities [1]. There are other classification schemes that have developed as well. In particular the comprehensive SAE Standard J3016. It distinguishes between six categories with levels 0 (no automation), 
1 (driver assistance) and 2 (partial automation) subsumed under the headline "human driver monitors the driving environment" and 3 (conditional automation), 4 (high automation) and 5 (full automation) labeled as "automated driving systems" (see also section 8.4.6 for the BASt classification scheme).

\subsubsection{Japan}

Influenced by Google's lobbying at the state level in the United States, Japan has begun to exhibit more interest in autonomous vehicles. Japan is renowned both for its robotic technologies and its low-carbon vehicle technologies. In 2013, Nissan received approval from the Japanese authorities to test its self-driving car, the Nissan Leaf. The Leaf is the first car that combines an electric motor with an advanced driver assistance system [3]. Kanagawa Governor Yuji Kuroiwa and Nissan Vice Chairman Toshiyuki Shiga tested the car on the Sagawa Expressway near Yokohama [38]. Prime Minister Shinzo Abe also has tested several "self-driving cars" produced by Japanese manufacturers Toyota, Honda, and Nissan and has claimed that he senses "that the Japanese technology is the world's best" [39]. "In particular, in tough driving conditions such as tight curves and lane changing using autonomous driving, I think our Japanese technologies are among the world's best" [37]. The competition to be a leader in the field is clearly heating up and politicians are lending their visibility and weight to support this emerging technology.

\subsubsection{United Kingdom}

The situation of the United Kingdom is emblematic of the situation in many European states. There is growing concern that national automobile developers are being hampered by regulatory restrictions and lack of a clear political strategy for autonomous vehicles. A September 2013 advise of the British Houses of Parliament, Parliamentary Office of Science \& Technology notes, "There is no explicit legislation which governs autonomous vehicles on UK roads". The advice further laments: "At present there is no published strategy for the adoption of autonomous vehicles in the UK" [29]. As is the case with several other European member states, steps to improve the possibilities for testing are being taken. The British Ministry of Science and Universities has designated $£ 6$ million for research and technology into autonomous vehicle technologies and the Department for Transport is permitting trials on public roads.

\subsubsection{Sweden}

Sweden is an early pioneer of self-driving technology. The Swedish Government signed a memorandum of understanding with Volvo to allow ordinary people to use self-driving 
cars. The project involves the Swedish Transport Administration, Lindholmen Science Park and the City of Gothenburg. It is the first project that aims at testing autonomous vehicles on a larger scale with regular citizens. The project which started in 2014 aims at putting 100 autonomous vehicles onto a $50 \mathrm{~km}$ long road in Gothenburg by $2017 / 2018$. It also sets the year 2020 as a timeline for when the first autonomous cars will be available for general usage [28].

The collaboration between the Swedish government and Volvo in this project suggests that in Sweden there is political recognition of the potential importance of this new technology. Swedish public officials highlight not only the safety dimensions of the new technology but also other sustainability factors. Ms. Catharina Elmsäter-Svärd, the infrastructure minister listed the many challenges to be tackled in the years to come that would be addressed by autonomous vehicles. These included environment, climate change, space, and traffic safety. In Europe, there appears to be a stronger linking of broad sustainability themes to driver-less cars than is the case in the United States [50].

Claes Tingvall from the Swedish Transport Administration explained why co-operation between the government and Volvo makes sense. Such co-operation can help address legislative questions regarding the new technology early on. At the same time, the societal benefits from the new technology can be incorporated into policy more generally: "We can make traffic as a whole safer, smoother, less polluting, but also try to build infrastructure in a quite different way". Minister Elmsäter-Svärd noted: "This project is very unique and the expectation from the Swedish government is still to be in the lead when it comes to road safety. We know that livability, environment issues and also road safety is so close together in the project." Noteworthy, is that the inscription on the Volvo self-driving car states: "Drive Me. Self-driving cars for sustainable mobility" [50].

\subsubsection{Germany}

In Germany, autonomous driving vehicles are in the testing phase. For public demonstration purposes, the former Minister for Research and Development, Annette Schavan tested the autonomous driving vehicle, "MadeInGermany", developed at Freie Universität Berlin. AutoNOMOS - Autonomie- und Fahrerassistenzsysteme für Pkw und Lkw" - was supported with 2.2 Million euros by the Research Ministry. In an interview, Minister Schavan mentioned the necessity for further innovation of the technology as it could enhance the mobility of elderly and handicapped people [41]. Apart from AutoNOMOS, various other research projects in Germany have helped to advance an increase in automation towards autonomous driving, including the Technical University of Braunschweig's Stadtpilot and TU Darmstadt's' Conduct-by-Wire projects [46], [47].

The research ministry, which is interested in supporting innovative technologies and advancing technological niches, has set incentives to promote research on autonomous driving. The ministry's high-tech mobility strategy stresses links among energy policy, e-mobility and intelligent logistics. It further stresses the role of ICT applications in the 
automotive industry, although it does not focus explicitly on autonomous driving [11]. Not only has the research ministry funded research on autonomous driving, there are currently more projects underway funded by the Federal Ministry for Economic Affairs and Energy, one of which is the project aFAS. It is set up to develop a driverless vehicle to protect construction sites on highways [45].

The Federal Highway Research Institute has - similarly to the NHTSA - elaborated a nomenclature to facilitate the legal assessment of different degrees of automation. The nomenclature distinguishes "driver only" and "assisted" systems from systems with "partial automation" (the system takes over lateral and longitudinal control in certain situations), "high automation" (the driver does not need to continuously monitor the system) and "full automation" (the system fully takes over lateral and longitudinal control) [25]. This categorization is widely accepted by German experts, bureaucrats, and political stakeholders.

The German automotive industry has begun pushing for change. Partnering with Nokia, Mercedes-Benz responded to the Google challenge in August 2013 with the S 500 Intelligent Drive Autonomous Car long-distance test drive. Following the path Bertha Benz travelled in her historic 1888 long-distance road trip, the S 500 Intelligent Drive vehicle successfully drove on its own between Mannheim and Pforzheim (with a driver behind the wheel as a back-up). Audi, BMW, and auto-suppliers Bosch and Continental Automotive Systems are working on autonomous and semi-autonomous vehicle technologies as well [40].

The German government has not, however, responded with new regulatory initiatives or an explicit strategy to push the implementation of autonomous driving. Rather, governmental actors are focused on other technology options that rather conform to European discourses of sustainable mobility. These are linked to the broader over-arching policy towards a low-carbon energy transformation. E-mobility, for example, is not only backed by a strategic governmental document but is also repeatedly affirmed in speeches by highlevel politicians, including the chancellor [9], [10].

The VDA is one of the technology's strongest proponents lobbying for regulatory change. It is one of the few actors that has expressed a clear vision for autonomous driving in its publications. The VDA has organized conferences centered on vehicle automation, the connected car and autonomous driving. The VDA envisions autonomous driving to be a widespread reality in the future. The association has illustrated concrete steps to be taken on the way towards a self-driving future, such as Lane Changing Support, improved human-machine-interface, and longitudinal guiding assistance [48]. In addition, supply companies have an interest in pushing a higher degree of automation in vehicles and, consequently, autonomous driving [6].

The main national arena addressing autonomous driving is a round table initiated and run by the Transport Ministry. On the working level, the participants are trying to institutionalize a stakeholder dialogue as a first step in getting the issue more strongly on the German policy agenda. The approximately 45 round table members meet twice a year. They consist of representatives of the German Association of Automotive Industry (Verband der 
Automobilindustrie, VDA), representatives of automotive manufacturers, the Ministry of Transport, the Federal Highway Research Institute (BASt), the Federal Motor Transport Agency (KBA), the Ministry of Justice, the Ministry of Economy and Energy, representatives of science and research (e.g. Fraunhofer Institute, German Aerospace Center (DLR), Universities) and associations (such as the Association of International Motor Vehicle Manufacturers (Verband der internationalen Kraftfahrzeughersteller, VDIK), the German Insurance Association (Gesamtverband der Deutschen Versicherungswirtschaft, GDV), the German Automobile Club (Allgemeiner Deutscher Automobilclub, ADAC), and the Association of the Technical Control Boards (Verband der TÜVs)). Three working groups have been established and meet four times a year. The working groups are concerned with legal questions, issues tied to drivers and vehicles including type approval, and research.

The focus on type approval - the procedure whereby an EU Member State certifies that a type of vehicle, system, component or separate technical unit satisfies the relevant administrative provisions and technical requirements [23] - in the second working group on driver and vehicle shows that the round table aims at dealing with many issues at a technical and rather low regulatory level (compared to more general legal questions that would require changes in regulatory law or in the road traffic act). Many aspects of automation do not touch upon regulated aspects and would be generally allowed since they are not defined under the UNECE system. Higher level legal aspects would be in the realm of the Ministry of Justice but are currently not dealt with.

The topics discussed at the round table address highly automatized vehicles but tend not to address fully automated driving technologies. The round table talks are to some degree strategic in that they aim at putting or keeping the topic on the policy agenda. It is not so much about visions but about attempts to show progress in practice. However, the whole process is neither very transparent, nor very visible - meeting discussions are not documented for the general public and societal stakeholders are not widely included. There is also little exchange with European platforms on autonomous driving.

Different views regarding the importance of amending the Vienna Convention were expressed in Germany. The amendment was welcomed by Thomas Weber, head of group research at Daimler and head of development at Mercedes-Benz who was quoted as saying: "Today I am only allowed to take my hands off the wheel to a limited extent. Thankfully the Vienna Convention on Road Traffic has been changed" [40]. Other German experts did not see the convention as so much of a hindrance in relation at least in regard to highly, but not fully-automated vehicles. By definition, in highly automated vehicles, a driver would always be expected to be present and able to take over control and monitor traffic as expected by current legislation. These experts considered amendments to public regulatory law, which have not yet occurred, to be more important [25], [43]. In a personal interview, Dr. Christoph Hecht from the German Automotive Club, ADAC, representing the consumer perspective explained that a customer has no incentive to buy a highly automated vehicle unless they are allowed to make use of it. 


\subsection{Analysis}

Autonomous driving is only slowly emerging as a concept known to all but a small community of experts. It is not deeply anchored in European mobility discourses, strategies, or outlooks. Yet there is some linking of autonomous driving technologies to other strategic concerns, including competitiveness of the automotive industry, sustainable mobility, safety, and the elderly. The framing of autonomous driving varies by national context, reflecting the dominant concerns of different regions. In the United States, where there are over 30,000 traffic deaths each year, safety issues are brought to the fore. In Japan, which has been faced by a long economic slump, competitiveness is a top priority. In Sweden, autonomous driving is being linked to sustainable mobility. In Germany, it is high-end automobiles that are being fitted with autonomous driving technology, suggesting the importance of being at the technological cutting edge in the luxury automobile market. As autonomous vehicle technologies advance, debates in Europe and abroad may shift, but for the time being it appears that the commercialization and wide-spread use of fully automated driving vehicles remains a distant vision.

Innovations in autonomous driving technologies are being presented as important for technological leadership in the automobile sector across all of the jurisdictions examined here even if autonomous vehicles are not yet seen as commercially viable.

In the United States, regulatory competition is emerging among states eager to be seen as frontrunners in systems that could make traffic safer and traffic flows smoother. Statelevel actors are boasting their regulatory initiatives to show their state's technological leadership. Leadership in realizing "science fiction" visions may be important for longterm competitiveness. This could either be seen as a kind of "Delaware effect", with states competing to attract industries to their region with the provision of favorable regulatory environments, or conversely, a "California effect," where states compete with each other by establishing the more advanced regulatory standards to promote technological innovation and competitive advantage within their own states [49].

In Japan, politicians are sending the message to consumers (both domestic and overseas) that autonomous driving technologies can be linked to Japanese technological strengths in robotics, electro-mobility and energy efficiency, to produce next generation automobiles. The Swedish government is among the most ambitious in its aim to commercialize autonomous driving vehicles by 2020 and set "sustainable mobility" into motion.

The German government has done little to initiate broader discussions about autonomous driving. While the Transport Ministry has organized a stakeholder platform at the national level, it has not tried to stimulate wider public debates at the German national level or as part of official consultations at the European level. The main push for greater discussion and strategizing has come from stakeholders. Volvo, for example, has been quite active at the EU level as has the German automobile association (VDA). Also component suppliers such as Continental and ICT companies have lobbied for more support. 
Although by no means definitive, the research conducted here suggests some other interesting patterns that deserve further attention as well as some soft and preliminary conclusions.

First, the kind of regulatory competition seen in the United States, may be spreading to the international level as countries vie with each other for technological leadership in a newly emerging field. Autonomous driving is not only about the automotive industry but about many other industrial branches that will profit from a higher degree of automation such as component suppliers. This is why there is a growing interest in promoting locational advantages and why political commitments are starting to be made in some countries to support certain development paths.

Second, smaller automobile companies (e. g. Volvo, Nissan) and non-traditional players (e.g. Google) moved earlier with autonomous vehicle technologies to gain public and political attention compared with the bigger, more established automotive manufacturers (including German manufacturers). One might read into this that given that autonomous driving technologies are still at early stages of development, larger companies have been wary about taking reputational risks with still unproven technologies. Smaller companies may be more willing to take such risks since they are dependent on leadership advantage. Geels argues that incumbent firms' interest in radical and transformative change is generally not very high since incumbents have typically sunk investments in existing technologies, skills, and people. He further points to the characteristics of more radical changes being riskier and leading to changes that may not match existing competencies [27].

Third, autonomous vehicles are portrayed as highly innovative and demonstrative of a nation's technological (and economical) leadership capabilities by stakeholders, yet political leaders have not played much of a role in trying to promote autonomous vehicle technology in public. Fully automated vehicle technology is in an early development stage. How it fits into dominant strategic visions for mobility or how realistic commercialization of the technology is, is still not clear which may explain why only limited political actions have been taken.

Fourth, the Zero-Accident-Vision has been an important message for developers of autonomous vehicles and component suppliers. The vision appears to play a larger role in the United States where there are higher fatality rates than is the case in Europe or Japan although in all countries considered, greater use of remote sensing and other technologies is seen as a means of improving traffic safety.

Fifth, links to efficiency and environmental protection are found in all countries, but are especially strong in Japan and Europe. And within Europe, Sweden is pursuing this image quite aggressively.

Sixth, there are many unsolved questions with regard to accountability, data protection, the legal framework as well as social and ethical considerations. These issues are only slowly beginning to be debated. The possible impacts of autonomous driving on mobility behaviours and human-machine interactions as well as data protection and acceptance aspects will need to be studied and addressed. Indeed, nowhere has there been much political attention paid to the societal implications of greater use of autonomous vehicle 
technologies even though there are many non-technical aspects that must be considered (Ch. 29). These include the development of appropriate regulations covering technological, safety, and liability standards as well as rules of the road for autonomous vehicles. There remain also many unanswered questions with regard to public regulatory law, licensing law and liability law in the countries considered (Ch. 25).

Seventh, perhaps reflective of the fact that autonomous vehicles are still only in early pilot testing phases, few efforts have been made to develop future mobility scenarios in which autonomous driven vehicles play a central role (Ch. 11). In Europe, the driverless-car vision has not been embedded in an overall strategy for realizing sustainable mobility.

Finally, where the most governmental activity can be seen is in providing support for research and development of autonomous vehicle technologies. States that are lagging behind technologically are scrambling to catch up by supporting more research and development. There are still critical technical issues that need further developing before a widescale application of autonomous driving can be considered and this provides opportunities for new entrants. There are also uncertainties regarding which technologies may win out in the long run.

\subsection{Conclusion}

Since there are already numerous technological solutions being implemented that are linked to various societal goals (e. g. e-mobility, intermodal solutions, strengthening public transport), autonomous driving will have to be debated in the context of these (competing or complementary) technological paths. Discussions about future mobility possibilities and the role that could be played by autonomous or partially or highly automated vehicles should be more inclusive. It should not be restricted to an arena primarily concerned with technical and legal questions such as the round table in Germany. Other stakeholders such as non-governmental organizations or think tanks could be integrated into existing structures (stakeholder platforms, legal processes, etc.), but new arenas could also be created. In parallel, advisory bodies could be set up to assess not only technological advancements and needs, but also social, environmental, and regulatory implications of greater use of autonomous driving technologies.

\section{References}

1. Aldana, K.: U.S. Department of Transportation Releases Policy on Automated Vehicle Development. http://www.nhtsa.gov/About+NHTSA/Press+Releases/U.S.+Department+of+Transportation+ Releases+Policy+on+Automated+Vehicle+Development. Accessed 21 July 2014

2. Brown, E.G.: Governor Brown Signs Bill to Create Safety Standards for Self-Driving Cars. http://gov.ca.gov/news.php?id=17752. Accessed 10 July 2014

3. Beissmann, T.: Nissan Leaf becomes Japan's first road-legal autonomous vehicle. http://www. caradvice.com.au/253761/nissan-leaf-becomes-japans-first-road-legal-autonomous-vehicle/. Accessed 10 July 2014 
4. CARS 21 High Level Group on the Competitiveness and Sustainable Growth of the Automotive Industry in the European Union: Final Report 2012, 6 June 2012

5. Clark, M.: States take the wheel on driverless cars. http://www.usatoday.com/story/news/ nation/2013/07/29/states-driverless-cars/2595613/. Accessed 10 July 2014

6. Continental: Automated Driving: Adapting the Legal Framework in Line with Market Dynamics. http://www.continental-corporation.com/www/pressportal_com_en/themes/press_releases/ 1_topics/automated_driving_en/pr_2014_07_07_zulieferer_innovativ_en.html. Accessed 10 July 2014

7. Convention on Road Traffic. http://www.unece.org/fileadmin/DAM/trans/conventn/Conv road_traffic_EN.pdf. Accessed 21 July 2014

8. Department of Motor Vehicles: Autonomous Vehicles. http://www.dmvnv.com/autonomous.htm. Accessed 21 July 2014

9. Die Bundesregierung: Nationaler Entwicklungsplan Elektromobilität der Bundesregierung, August 2009. http://www.bmbf.de/pubRD/nationaler_entwicklungsplan_elektromobilitaet.pdf. Accessed 10 July 2014

10. Die Bundesregierung: Rede von Bundeskanzlerin Merkel bei der Internationalen Konferenz „Elektromobilität bewegt weltweit“, Berlin, 27. Mai 2013. http://www.bundesregierung.de/ ContentArchiv/DE/Archiv17/Reden/2013/05/2013-05-27-merkel-elektromobilitaet.html; jsessionid=AE3DA68C72591889A70E1C05B8F4C0D2.s2t2?nn=437032. Accessed 10 July 2014

11. Die Bundesregierung: Fahrzeug und Verkehrstechnologien. http://www.hightech-strategie.de/ de/325.php. Accessed 10 July 2014

12. Edler, J. Kuhlmann, S. Smits, R.: New Governance for Innovation. The Need for Horizontal and Systemic Policy-Coordination, Report on a Workshop held at the occasion of the 30th anniversary of the Fraunhofer Institute for Systems and Innovation Research (ISI), Karlsruhe, November 2002. Fraunhofer ISI Discussion Papers Innovation System and Policy Analysis, No. $2(2003)$

13. Edquist, C.: Systems of Innovation Approaches - Their Emergence and Characteristics. In: Edquist, C. (ed.) Systems of Innovation: Technologies, Institutions and Organisations, pp. 1-35. Pinter Publishers/Cassell Academic, London (1997)

14. Edquist, C. Innovation Policy - A Systemic Approach. In: Archibugi. D., Lundvall, B.Å. (eds.) The Globalizing Learning Economy. Oxford Scholarship Online (2003) DOI:10.1093/019925 8171.003.0013

15. Edquist,C., Hommen,L., Johnson, B., Lemola, T., Malerba, F., Smith, K.: The ISE Policy Statement: The Innovation Policy Implications of the 'Innovation Systems and European Integration' (ISE) Research Project, University Unitryck, Linköping (1998)

16. Ertico ITS Europe: Towards Futurama - Developments in Road Transport Automation. http://www.ertico.com/towards-futurama-developments-in-road-transport-automation/. Accessed 10 July 2014

17. European Commission: Communication from the Commission. Europe 2020. A strategy for smart, sustainable and inclusive growth. $\operatorname{COM}(2010) 2020$ final

18. European Commission: White Paper. Roadmap to a Single European Transport Area - Towards a competitive and resource efficient transport system. COM (2011) 144 final

19. European Commission: Communication from the Commission to the Council and the European Parliament. Research and innovation for Europe's future mobility. Developing a European transport-technology strategy. COM (2012) 501 final

20. European Commission: Communication from the Commission to the European Parliament, the Council, the European Economic and Social Committee and the Committee of the Regions. CARS 2020: Action Plan for a competitive and sustainable automotive industry in Europe. COM (2012) 636 final 
21. European Commission: Horizon 2020 Work Programme 2014-2015. 11. Smart, green and integrated transport. European Commission Decision C (2013)8631 of 10 December 2013

22. European Commission: Horizon 2020 Work Programme 2014-2015. 5. Leadership in enabling and industrial technologies. European Commission Decision C (2014)2690 of 29 April 2014

23. European Parliament and the Council of the European Union: Directive 2007/46/EC of 5 September 2007establishing a framework for the approval of motor vehicles and their trailers, and of systems, components and separate technical units intended for such vehicles

24. European Parliament and the Council of the European Union: Directive 2010/40/EU of 7 July 2010 on the framework for the deployment of Intelligent Transport Systems in the field of road transport and for interfaces with other modes of transport

25. Federal Highway Research Institute: Legal consequences of an increase in vehicle automation. Consolidated final report of the project group, Part 1., Bundesanstalt für Straßenwesen, Bergisch-Gladbach http://www.bast.de/DE/FB-F/Publikationen/Download-Publikationen/ Downloads/F-legal\%20consequences.pdf?_blob=publicationFile. Accessed 10 July 2014

26. Geels, F. W.: From Sectoral Systems of Innovation to Socio-Technical Systems. Insights About Dynamics and Change from Sociology and Institutional Theory. Research Policy, 33, 897-920. (2004)

27. Geels, F.: Reconceptualising the co-evolution of firms-in-industries and their environments: Developing an inter-disciplinary Triple Embeddedness Framework. Research Policy 43, 261277 (2014)

28. Grünweg, T.: Pilotprojekt "Drive Me": Geisterfahrt in Göteborg. http://www.spiegel.de/auto/ aktuell/autonomes-fahren-pilotprojekt-drive-me-von-volvo-in-goeteborg-a-972134.html. Accessed 10 July 2014

29. Houses of Parliament, Parliamentary Office of Science \& Technology: Autonomous Road Vehicles. PostNote, No. 443 (2013)

30. Jänicke, M. and Lindemann, S.: Governing Environmental Innovations: a new role for the nation state. Global Environmental Politics. 4(1), 29-47 (2010)

31. Jacob, K., Beise, M., Blazecjzak, J., Edler, D., Haum, R., Jänicke, M., Löw, T., Petschow, U., Rennings, K.: Lead Markets for Environmental Innovations. Heidelberg: Physica. ZEW Economic Studies 27 (2005)

32. Jacob, K., Jänicke, M.: Lead Markets for Environmental Innovations. A New Role for the Nation State. Global Environmental Politics. 4 (1), 29-46 (2004)

33. Kim, M.K., Heledii, Y., Asheriji, I. Thompsoniy, M.: Comparative analysis of laws on autonomous vehicles in the U.S. and Europe. http://www.auvsishow.org/auvsi2014/Custom/Handout/ Speaker8657_Session789_1.pdf. Accessed 21 July 2014

34. Martini, C.: Seminar explored policy and legal implications surrounding the adoption of autonomous driving in Europe. Press release. http://pr.euractiv.com/pr/adoption-autonomous-driving-europe-debate-starts-eu-level-97552. Accessed 21 July 2014

35. Miethling, B.: Politische Triebkräfte der Innovation. Peter Lang, Frankfurt am Main (2012)

36. Negro S.O.: Dynamics of Technological Innovation Systems. The Case of Biomass Energy. Labor Grafimedia, Utrecht (2007)

37. Nissan: Japan Prime Minister Abe Goes Public with Autonomous Drive Car. http://reports. nissan-global.com/EN/?p=13496. Accessed 10 July 2014

38. Prigg, M.: Nissan's 'Tron' self-driving car becomes first to be allowed on Japanese highways. http://www.stuff.tv/google/nissan-dumps-driver-self-driving-cars-becomes-first-be-allowedjapanese-roads/news. Accessed 21 July 2014

39. Quigley, J.T.: Japanese Prime Minister “Test Drives" Autonomous Vehicles. http://thediplomat. com/2013/11/japanese-prime-minister-test-drives-autonomous-vehicles/. Accessed 10 July 2014 
40. Reuters: Cars could drive themselves sooner than expected after European push. http://www. reuters.com/article/2014/05/19/us-daimler-autonomous-driving-idUSKBN0DZ0UV20140519. Accessed 21 July 2014

41. Rothmund, S.: Ministerin testet selbststeuerndes Fahrzeug. http://www.fu-berlin.de/campusleben/newsletter/1209/1209_schavan.html. Accessed 10 July 2014

42. Schorsch, P.: Rep. Jeff Brandes' 'Google Car' Legislation Drives Forward. http://stpete.patch. com/groups/peter-schorschs-blog/p/bp--rep-jeff-brandes-google-car-legislation-drives-forward. Accessed 10 July 2014

43. Smith, B.W.: Automated Vehicles are Probably Legal in the United States. The Center for Internet and Society, CIS, Stanford (2012)

44. Smith, B.W.: SAE Levels of Driving Automation. http://cyberlaw.stanford.edu/blog/2013/12/ sae-levels-driving-automation. Accessed 10 October 2014

45. Stolte, T., Bagschik, G., Reschka, A. and Maurer, M.: Automatisch fahrerlos fahrendes Absicherungsfahrzeug für Arbeitsstellen auf Autobahnen (aFAS) Konferenzbeitrag beim 16. Braunschweiger Symposium AAET 2015 am 12./13. Februar 2015. http:/www.its-nds.de/media/ veranstaltungen/aaet/AAET_2015_Programm_Screen_Ausfuellbar2.pdf. Accessed 10 March 2015

46. Technical University Braunschweig: Das Projekt Stadtpilot. https://www.tu-braunschweig.de/ stadtpilot. Accessed 10 March 2015

47. Technical University Darmstadt: Mit dem Fahrzeug gemeinsam fahren - Conduct-by-Wire 2. http://www.iad.tu-darmstadt.de/forschung_15/forschungsschwerpunkte_1/fahrzeugergo_1/conductbywire_6.de.jsp. Accessed 10 March 2015

48. VDA: Vernetzung. Die digitale Revolution im Automobil. http:/www.vernetzung-vda.de/upload/vda05/downloads/magazin/VDA_Magazin_Vernetzung.pdf. Accessed 10 July 2014

49. Vogel, D.: Trading Up: Consumer and Environmental Regulation in a Global Economy. Harvard University Press, Cambridge (1995)

50. Volvo Car Germany 2013 https:/www.media.volvocars.com/de/de-de/media/videos/136535/ drive-me-selbstfahrende-autos-fr-eine-nachhaltige-mobilitt-newsfeed. Accessed 10 July 2014

51. Weiner, G. and Smith, B.W.: Automated Driving: Legislative and Regulatory Action. cyberlaw. stanford.edu/wiki/index.php/Automated_Driving:_Legislative_and_Regulatory_Action. Accessed 17 June 2014

52. Whaley, S.: Gov. Sandoval ‘Taken For Ride' In Google Self-Driving Car. http://www.nevadanewsbureau.com/2011/07/20/gov-sandoval-\%E2\%80\%98taken-for-ride\%E2\%80\%99-in-google-self-driving-car/. Accessed 10 July 2014 